\title{
Assessment of the Role of Community of Practice on Performance: A Case of Public Service in Makueni County Government, Kenya
}

\author{
Justus Kaminda Kisilu*, Godfrey Kinyua \\ Department of Business Administration, School of Business, Kenyatta University, Nairobi, Kenya \\ Email address: \\ kamindakis@yahoo.com (J. K. Kisilu),jefkinyua@gmail.com (G. Kinyua) \\ ${ }^{*}$ Corresponding author
}

To cite this article:

Justus Kaminda Kisilu, Godfrey Kinyua. Assessment of the Role of Community of Practice on Performance: A Case of Public Service in Makueni County Government, Kenya. Journal of Human Resource Management. Vol. 8, No. 1, 2020, pp. 11-15.

doi: $10.11648 /$ j.jhrm.20200801.12

Received: November 11, 2019; Accepted: December 11, 2019; Published: January 9, 2020

\begin{abstract}
The intense competition and change which occurs on a continuous and disruptive basis in the business environment requires organizations both private and public to enhance their performance at all times to survive. Successful utilization of firm knowledge through effective capturing, creation, sharing and transferring can improve the firm's effectiveness which in turn enhances the performance of the firm. The aim of this study was to examine the influence of community of practice on the performance of public service board in Makueni County, Kenya. This study made use of descriptive research design. The target population of this study was the employees of Makueni County government. Stratified sampling method was used to sample respondents so as to make sure that all the categories of the respondents are well represented. Simple random sampling method was used to select the respondents. The sample size for this study was 98 respondents. The 98 respondents were selected from all the 30 wards in Makunei County. The research data was collected using semi-structured questionnaires. Quantitative data gathered from closed-ended questions was analyzed using measures of central tendency and dispersion. Qualitative data gathered using open-ended questions was analyzed using content analysis. Presentation of findings was done using tables and charts. Multiple regression analysis was used to show the extent to which variables relate to each other. The study established that community of practice had a positive and significant relationship on organizational performance. The study concludes that community of practice helps in to learning and supporting one another in order to create, spread, retain, and use knowledge relevant to the organization. These networks are fostered and established in order to build strategic capabilities within the organization by leveraging learning and knowledge sharing. Communities of practice have the potential to improve organizational performance and, thereby, contribute to the reinforcement of an organization's long-term strategic advantages. The study also concludes that community of practice gives an organization access to knowledge and expertise that they would not easily gain on their own. This builds their confidence, enhances their quality of work, promotes personal development, and makes their work even more meaningful. The study recommends that management on the County government of Makueni should actively facilitate community work by providing required resources and by establishing necessary prerequisites in the organization. Design a structure that allows for variations in culture, language, organization, and work without sacrificing the development of trust and connection among diverse community members.
\end{abstract}

Keywords: Community of Practice, Organizational Performance, Public Service

\section{Introduction}

The intense competition and change which occurs on a continuous and disruptive basis in the business's environment requires organizations both private and public to enhance their performance at all times to survive [18]. As a result, most organizations have chosen to focus on effective utilization of their resources such as knowledge which is 
claimed to be a source of the company's competitive advantage [21]. Successful utilization of firm knowledge through effective capturing, creation, sharing and transferring can improve the firm's effectiveness which in turn enhances the performance of the firm [6].

The abilities of an organization to effectively utilize its resources and measure performance will determine its success. Effective firm performance measurement will enable the firm to know how well it is able to use its resources to generate revenue and also achieve its set operational objectives. Effective firm performance measurement will also enable the firm to identify if, how and when the firm is meeting the needs of its customers, to identifying success, improvement opportunities, to better understand processes and bottlenecks, to spot problems and also to identify waste [7].

Community of practice refers to a group of people that engage in the process of collective learning or share a skill, expertise or a profession. The group is formed naturally or can be created deliberately because of the member's common interest in a certain field. The goal of the group is mainly to gain knowledge and experience in a specific area which will help certain members develop personally and also professionally [10]. The idea of community of practice was first proposed in 1991 by Etienne Wenger, an educational theorist and Jean Lave, a cognitive anthropologist [10]. The two defined community of practice as a group of people that share a skill expertise or a profession and that it happens naturally or can be created deliberately because of the member's common interest in a certain field. Its goal is mainly gaining knowledge and experience in a specific are which will help certain members develop personally and also professionally. Where the members collaborate online via mobile phones, newsgroups or discussion boards [8].

\section{Statement of the Problem}

The public expect quality service from the Government. Delivery of quality public service in Makueni County Government requires high performance levels from the public service. Service delivery is promoted in education, health, social protection, culture and recreation, water and environment sectors. The ratio of health personnel to population remains low in Makueni County at 1:22,000 for doctors and 1:2,000 for nurses respectively. Makueni County has poor distribution and connectivity to electricity leading to households' dependency on unsustainable use of energy sources such as firewood and charcoal. Only 5.7 per cent of households in the County use electricity for lighting compared to a national average of 22.9 percent. The level of poverty in Makueni County stands at 60.6 percent which is higher than the national average of 45.2 percent (Kenya National Bureau of Statistics, 2015). Makueni County is generally dry and faced with acute water shortage that has a direct impact on economic development. It is estimated that the average distance to a water point is 8 kilometres. Makueni County has water coverage of 35.6 per cent against national water coverage of 52 per cent (Government of Makueni County, 2016).

Knowledge transfers has recently received considerable attention from the governments, non-governmental institutions and researchers and academicians due to the recent focus on effective knowledge management as a source of competitive advantage [19]. Through successfully capturing, transferring or sharing and creation, organizations can improve their effectiveness which in turn enhance their performance and also creates more possibilities to grow [6]. Since effective transfer of knowledge in organizations is crucial, costly and time consuming, organization needs to measure whether the transfer is successful. Unfortunately, organizations are not certain about the indicators of successful knowledge transfer hence the need for this study.

Past studies have been reviewed on knowledge transfer. For instance; [4] through their study established that knowledge is transferred through training, co-operation in research and development ( $\&$ D) and commercialization. This study was done in a foreign country and its findings might not apply in Makueni County. Further, the focus of the study was not on the effect of knowledge transfer on service delivery. [13] Determined information move in the social sciences and the humanities in public research organizations in Valencia and established that there is a strong presence of the public sector, commercial markets for knowledge in Valencia although they are not well developed. While this study was neither carried out in Kenya nor Makueni County, it also never addressed the impact of knowledge transfer on service delivery. [21] Examined strategic knowledge transfer as a source of competitiveness at Kenya Power and established that organizations transfer knowledge to their partners as well as between different departments within the organization. The study however was not based on the performance of Makueni County. [19] Examined the effect of knowledge transfer and spillover on product innovativeness among manufacturing SMEs in Kenya and established that knowledge transfer significantly enhance product innovativeness. However, the study focused on knowledge transfer and product innovativeness instead of firm performance. This brings a gap in knowledge that this study sought to fill through investigating the relationship between community of practice and the performance of public service board in Makueni County Government, Kenya.

\section{Theoretical Review}

\section{Knowledge Based View Theory}

The knowledge-based view was developed from the work of Grant (1996). The knowledge-based view builds upon the resource-based view which was developed by Penrose (1959). The knowledge-based theorists propose that for firms to attain long-term survival, they should focus on creation and accumulation competencies that are knowledge based since knowledge is the most crucial resource for the future of firms [20]. This theory thus highlights effective ways of integrating and coordinating the individual activities within 
the organization for the sustainability of firm competitive advantage hence performance.

The knowledge-based view further suggests that in firms, heterogeneous knowledge capabilities and bases are the major determinants of the firm's sustained competitive advantages and superior firm performance since they are socially complex and also difficult to copy or imitate. Knowledge in an organization can be carried or is embedded in firm entities such as culture, policies, identities, routines, documents, systems and employees. This theory is however criticized by [1] on the grounds that it does not go far enough. The theory is also criticized for treating knowledge as a generic resource and not having special characteristics. The theory is also criticized for not being able to distinguish between different types of capabilities that are knowledge based.

This theory is relevant to this study for considering knowledge as a strategically significant resource of a firm that when exploited well. This helps a firm to earn competitive advantage which will enhance the performance of the firm. The theory sheds light on how a firm can attain long-term survival by focusing on creation and accumulation of competencies that are knowledge based. This theory links community of practice variable.

\section{Literature Review}

[12] Examined how communities of practice and organizational performance. The study findings were based on an examination of seven organizations that acknowledged communities of practice created value. Communities of practice enhance factors such as a common language and context which can be shared among members of the community, connection of practitioners who may or may not be collocated, build relationships that promote trust and mutual obligation. The study also established that sponsoring and supporting communities of practice groups whose members regularly participate in sharing and learning, based on common interests can improve the performance of the organizational.

[9] Through a process-oriented study examined the effect of communities of practice on the performance of firms in Korea. The researchers identified three determinants that affect participation in communities of practice. The study used data from 122 firms that were headquartered in Korea.
The study established communities of practice enhance knowledge exchange which in turn improves the firm's operational performance and also the general performance of the firm.

[17] Empirically investigated the relationship between communities of practice and the performance of firms. The study used data from interviews, surveys, and company record. The study focused on several communities of practice that were within a multi-billion dollar construction project. The researchers established that there were three communities of practice which operated under stable conditions. The three communities of practice were found to enhance the performance of the projects. The study also found that when community of practice experiences changes in its communication channels due to say physical move, it will not be was never be able to regain its previous ability to continuously improve performance. The researchers thus concluded that there is a strong relationship between communities of practice and performance since communities of practice enhances the firm's communication channels.

\section{Research Methodology}

This study made use of descriptive research design. The target population of this study was the employees of Makueni County government. Stratified sampling method was used to sample respondents so as to make sure that all the categories of the respondents are well represented. Simple random sampling method was used to select the respondents. The sample size for this study was 98 respondents. The 98 respondents were selected from all the 30 wards in Makunei County. The research data was collected using semistructured questionnaires. Quantitative data gathered from closed-ended questions was analyzed using measures of central tendency and dispersion. Qualitative data gathered using open-ended questions was analyzed using content analysis. Presentation of findings was done using tables and charts. Multiple regression analysis was used to show the extent to which variables relate to each other.

\section{Findings}

The study sought to understand the extent at which an institution adopted Community of Practice as a means of knowledge transfer. Likert scale of 1-5 where: $1=$ No Extent; 2=Little Extent; 3=Moderate Extent; 4=Great Extent; 5=Very Great Extent was used. The findings are shown in Table 1.

Table 1. Community of Practice.

\begin{tabular}{|c|c|c|c|c|c|c|c|}
\hline Community of Practice & $\begin{array}{l}\text { No } \\
\text { Extent \% } \\
\end{array}$ & $\begin{array}{l}\text { Little } \\
\text { Extent \% } \\
\end{array}$ & $\begin{array}{l}\text { Moderate } \\
\text { Extent \% }\end{array}$ & $\begin{array}{l}\text { Great } \\
\text { Extent \% }\end{array}$ & $\begin{array}{l}\text { Very Great } \\
\text { Extent \% }\end{array}$ & Mean & $\begin{array}{l}\text { Std. } \\
\text { deviation }\end{array}$ \\
\hline Development of a common language & 8 & 17 & 28 & 10 & 37 & 3.76 & 1.05 \\
\hline Connection of practitioners & 10 & 25 & 15 & 25 & 40 & 3.82 & 1.12 \\
\hline $\begin{array}{l}\text { Build of relationships to promote trust and mutual } \\
\text { obligation }\end{array}$ & 6 & 8 & 19 & 29 & 38 & 3.77 & 1.10 \\
\hline Development of best practice standards & 2 & 12 & 20 & 25 & 41 & 3.83 & 1.15 \\
\hline Knowledge exchange among practitioners & 8 & 13 & 19 & 27 & 33 & 3.01 & 1.09 \\
\hline
\end{tabular}

Source: Research Data (2019). 
The findings in Table 1 shows that the respondents agreed that community of practice influence performance of public service in Makueni County, Kenya as indicated by the aggregate mean score of 3.64 and which vary significantly as shown by the standard deviation of $1.10 .37 .8 \%$ agreed to a very great extent, $23.2 \%$ to great extent, $20.2 \%$ great extent, $15 \%$ moderate extent and $6.8 \%$ no extent. This is in line with the findings of [2] which found that there was a significant positive relationship between community practice and performance as well as individual performance.

From the above table, the institution has adopted development of a common language as a means of knowledge transfer through leadership mentorship, 37\% agreed to a very great extent, $10 \%$ agreed to a great extent, $28 \%$ agreed to a moderate extent, $17 \%$ agreed to a little extent and $8 \%$ completely disagreed. The scale mean for the item was $3.76(\mathrm{~m}=3.76)$ which depicts an inclination towards agreement with the standard deviation of 1.01 indicating a small degree of variation of the responses from others. These findings agree with [11] study which show that the social capital resident in communities of practice leads to behavioral changes, which in turn positively influence business performance. Intense.

On the Connection of practitioners, $40 \%$ agreed to a very great extent, $25 \%$ agreed to a great extent, $15 \%$ agreed to a moderate extent, $25 \%$ agreed to a little extent and $10 \%$ completely disagreed. The scale mean for the item was 3.76 $(m=3.76)$ which depicts an inclination towards agreement with the standard deviation of 1.12 indicating a small degree of variation of the responses from others. These findings are supported by [17] study which focused on improved organizational performance through communities of practice and found that connection of practitioners was found to exhibit improved performance.

On the Build of relationships to promote trust and mutual obligation, $38 \%$ agreed to a very great extent, $29 \%$ agreed to a great extent, $18 \%$ agreed to a moderate extent, $8 \%$ agreed to a little extent and $6 \%$ completely disagreed. The scale mean for the item was $3.77(\mathrm{~m}=3.77)$ which depicts an inclination towards agreement with the standard deviation of 1.10 indicating a small degree of variation of the responses from others. This is in support of [16] study which explored the potential of communities of practice for learning and collaboration in a higher education context and revealed that collaboration was improved by establishing networks and professional alliances and the development of these benefits influenced the promotion of new practices.

On development of best practice standards, $41 \%$ agreed to a very great extent, $25 \%$ agreed to a great extent, $20 \%$ agreed to a moderate extent, $12 \%$ agreed to a little extent and $2 \%$ completely disagreed. The scale mean for the item was 3.83 $(m=3.83)$ which depicts an inclination towards agreement with the standard deviation of 1.15 indicating a small degree of variation of the responses from others. These findings agree with [3] study which identified, a set of levers that allows the community to evolve in this model increasing its effectiveness.
On Knowledge exchange among practitioners, 33\% agreed to a very great extent, $27 \%$ agreed to a great extent, $19 \%$ agreed to a moderate extent, $13 \%$ agreed to a little extent and $8 \%$ completely disagreed. The scale mean for the item was $3.01(\mathrm{~m}=3.01)$ which depicts an inclination towards agreement with the standard deviation of 1.09 indicating a small degree of variation of the responses from others. This is in view of a study carried out by [14] which found that knowledge sharing has strong influence on organizational performance as a second latent variable.

\section{Conclusions and Recommendations}

The study concludes that community of practice helps in to learning and supporting one another in order to create, spread, retain, and use knowledge relevant to the organization. These networks are fostered and established in order to build strategic capabilities within the organization by leveraging learning and knowledge sharing. Communities of practice have the potential to improve organizational performance and, thereby, contribute to the reinforcement of an organization's long-term strategic advantages. The study also concludes that community of practice gives an organization access to knowledge and expertise that they would not easily gain on their own. This builds their confidence, enhances their quality of work, promotes personal development, and makes their work even more meaningful.

The study recommends that management on the County government of Makueni should actively facilitate community work by providing required resources and by establishing necessary prerequisites in the organization. Design a structure that allows for variations in culture, language, organization, and work without sacrificing the development of trust and connection among diverse community members.

\section{References}

[1] Alevi, M. \& Leidner, D. E. (2001). Review knowledge management and knowledge managements systems. MIS Quarterly, 25 (1), 107-136.

[2] Cai, W., \& Klyushina, U. (2009). Talent retention and development within multinational company in China.

[3] Corso, M., \& Giacobbe, A. (2015). Building Communities of Practice that work: a case study based research. In The Sixth European Conference on Organizational Knowledge, Learning, and Capabilities, 4 (2), 17-19.

[4] Finne, H., Day, A. Piccaluga, A. Spithoven, A. Walter, P. \&Wellen, D. (2011). A Composite Indicator for Knowledge Transfer Report from the European Commission's Expert Group on Knowledge Transfer Indicators.

[5] Grant, R. M. (1996). Towards knowledge based theory of the firm. Strategic Management [Journal, (17), winter special issue. 109-122].

[6] Gray, K. (2011). The Ontario leadership framework 2012. With a Discussion of the Research. Foundations, 47 (7), 45-67. 
[7] Gunasekaran, A., \& Kobu, B. (2007). Performance measures and metrics in logistics and supply chain management: a review of recent literature (1995-2004) for research and applications. International journal of production research, 45 (12), 2819-2840.

[8] Kietzmann, J., Plangger, K. Eaton, B. Heilgenberg, K. Pitt, L. Berthon, P. (2013). Mobility at work: A typology of mobile communities of practice and contextual ambidexterity (PDF). Journal of Strategic Information Systems. 3 (4): 282-297.

[9] Koo. C., Ryoo, S. Wati, Y. \& Suh. Woojong (2009). Communities of Practice and Its Effects on Firm Performance: A Process-Oriented Study. KES-AMSTA International Symposium on Agent and Multi-Agent Systems: Technologies and Applications, 471-480.

[10] Lave, J., \& Wenger, E. (1991). Situated Learning: Legitimate Peripheral Participation. Cambridge: Cambridge University Press.

[11] Lesser, E. L. \& Storck, J. (2001). Communities of practice and organizational performance. IBM Systems Journal, 40 (4).

[12] Lesser, E. L., \& Storck, J. (2015). Communities of practice and organizational performance. IBM systems journal, 40 (4), 831-841.

[13] Martínez, E. C., Gallart, J. M. \& Penuela, J. O. (2012). Knowledge transfer in the social sciences and the humanities in public research organizations in Valencia. Working Paper $\mathrm{N}^{\mathrm{o}} 2010 / 12$.

[14] Ngah, R., \& Ibrahim, A. R. (2010). The effect of knowledge sharing on organizational performance in small and medium enterprises.
[15] Penrose, E. (1959). The Theory of the Growth of the Firm, Oxford University Press, Oxford.

[16] Sanchez-Cardona, I., Sanchez-Lugo, J., \& Vzlez-González, J. (2012). Exploring the potential of communities of practice for learning and collaboration in a higher education context. Procedia-Social and Behavioral Sciences, 46, 1820-1825.

[17] Schenkel, A., \&T eigland, R. (2018). Improved organizational performance through communities of practice. Journal of knowledge management, 12 (1), 106-118.

[18] Selvam, M., Gayathri, J., Vasanth, V., Lingaraja, K., \& Marxiaoli, S. (2016). Determinants of firm performance: A Subjective Model. International Journal of SocialScience Studies, 4 (2), 90-106.

[19] Gudda, P., Bwisa, H. \& Kihoro, J (2014). "Effect of Clustering on Product Innovativeness among Small and Medium Enterprises (SMES) in Kisumu County, Kenya. Journal of Marketing \& Technology, 4 (1), 35-49.

[20] Sigel, K., Hagemann, N. Leidel, M. \&Niemann, S. (2014). Insights regarding transdisciplinary and knowledge transfer gained from two case studies on integrated water resources management in Ukraine and Mongolia. Problem oriented projects and strategic research programs, 39 (4), 342-359.

[21] Teece, D. J. (2004). Royalties, evolving patent rights, and the value of innovation. Research Policy, 33 (2), 179-191.

[22] Wawira, I. R. (2013). Strategic knowledge transfer as a source of competitiveness at Kenya power. An unpublished project of the University of Nairobi. 